\title{
Correction to: Do metaphorical sharks bite? Simulation and abstraction in metaphor processing
}

\author{
Hamad Al-Azary ${ }^{1}$ - Albert N. Katz ${ }^{2}$
}

Published online: 12 January 2021

(C) The Psychonomic Society, Inc. 2020

\section{Correction to: Mem Cogn \\ https://doi.org/10.3758/s13421-020-01109-2}

There was an error introduced to the first paragraph of the section Metaphor as simulation during production of this article. The sentence reading:

From this perspective, the metaphor "lawyers are sharks" could engage bodily simulation processes as people create imaginative scenarios in which the metaphor makes sense (e.g., "lawyers are like sharks in moving quickly and aggressively toward their victims")(Wilson \& Gibbs, 2007, p. 729). Should have read:

From this perspective, the metaphor "'Lawyers are sharks' could engage bodily simulation processes as people create imaginative scenarios in which the metaphor makes sense (e.g., lawyers are like sharks in moving quickly and aggressively toward their victims)" (Wilson \& Gibbs, 2007 pg. 729). The original article has been corrected.

Publisher's note Springer Nature remains neutral with regard to jurisdictional claims in published maps and institutional affiliations.

The online version of the original article can be found at https://doi.org/ 10.3758/s13421-020-01109-2

Hamad Al-Azary

halazary@1tu.edu

1 Department of Humanities, Social Sciences and Communication, Lawrence Technological University, Southfield, MI, USA

2 Department of Psychology, University of Western Ontario, London, ON, Canada 